\title{
LEXONOMIC ANALYSIS OF RATE REGULATION
}

\author{
LEE LOEVINGER*
}

Government and business were more closely related in the 18 th century than today. For example, during the colonial period in America state legislatures frequently established prices for many items including.bread and other necessities. ${ }^{1}$ However, the system was challenged in 1776 when Adam Smith published his great work, The Wealth of Nations, and initiated an intellectual ferment that became part of the developing industrial and technological revolution. Under Smith's conceptual model of the free enterprise system, the public interest-and the wealth of the nation as a whole-was better served by an economic structure where each enterprise set prices in response to the impersonal forces of the market rather than government edict. This concept was so powerful and well adapted to the needs of the time that it gained wide acceptance in the following century and provided part of the intellectual framework for the Constitution. Moreover, operation of the American economy of the 19th century closely approximated Smith's conceptualization of the free enterprise system.

During the latter part of the 19th century, the growing power of large business aggregations created political demands for return to some measure of governmental control of pricing. In 1876, only a century after publication of Adam Smith's work, the Supreme Court held that a state legislature could constitutionally establish maximum prices to be charged by grain elevators since the elevators were engaged in a business affected with a "public interest.". A decade later Congress established the Interstate Commerce Commission to regulate railroad rates and services. In the 1920s and 1930s similar agencies were established or endowed with power to regulate rates and other activities of telegraph and telephone companies, power companies, interstate pipelines, and common

\footnotetext{
* Member, District of Columbia and Minnesota Bars. B.A. 1933, J.D. 1936, University of Minnesota.

Copyright 1969 and 1970 by Lee Loevinger. This article is an edited and revised version of a presentation made April 24, 1969, to the Conference on Public Utility Valuation and Rate Making, at Iowa State University, Ames, Iowa.

1. See New State loe Co. v. Liebman, 285 U.S. 262, 305-06 (1932) (dissenting opinion).
}

2. Munn v. Illinois, 94 U.S. 113 (1876). 
carriers. During the same period, the states commenced the regulation of the rates or prices of these and a myriad of other commercial activities.

The rate and price regulation of this early period was by direct legislative action. In contrast, governmental control of rates and prices in the 20th century has been almost exclusively through an administrative agency established by the legislature and endowed with delegated powers which are specified with varying degrees of clarity by statute.

The significant aspect of the growth of governmental control of prices in the 20th century is its development entirely on an ad hoc basis. In areas where a strong need or a powerful political demand for governmental action has been asserted, a regulatory agency has been established. However, no conceptual model of regulatory action has been postulated. Legally the regulatory agencies are regarded as agents of the legislature, exercising quasi-legislative power. ${ }^{3}$ Yet this approach fails to provide an understanding of how government can or, more importantly, should control economic activity.

The development of regulation has proceeded on the implicit assumption that regulation acts simply and directly to produce a desired result, and that the issuance of a rule or order by a regulatory agency accomplishes the mandate and purpose of that rule or order without complications. This assumption is uncritical, naive, and unrealistic. Neither theory nor observation establishes any simple relationship between regulatory action and the desired result. Theoretically, broadcasting licenses have no value and cannot be treated as property; yet the limitation on entry into the field of broadcasting has made licenses extremely valuable and has clearly affected prices and profits. Although the ICC was originally established to prevent exploitation of the public by the railroads through excessive or discriminatory rates, efforts in recent decades have largely been directed toward minimizing competition between railroads, motor carriers, and water carriers. Moreover, the $1 C C$ has often sought to increase rather than decrease rates.' In 1965 the

3. For a detailed discussion of the history and theory behind legislative "delegation of power" to regulatory agencies, se L. JAFFe, Judicial Control of Legislative Action 7 8, 33-40 (1965). See generally K. Davis, Administrative Law Text $\$ 1.05$ (1959) which discusses the quasi-judicial as well as the legislative role of the regulatory agency.

4. The influence of the "regulated" groups on ICC policy is noted in K. DAvIs, supra note $3, \S 1.03$, at 7 . 
Federal Communications Commission instituted its first formal broad-scale investigation of telephone rates..$^{5}$ Although the investigation has not been completed, clearly no agreement exists on determining either the rate base or a formula for establishing reasonable rates or even for exercising the Commission's regulatory power. ${ }^{6}$

Today we lack not only a rational theory of the regulatory function but also any general understanding of regulation itself. The term is commonly used to encompass the various forms of governmental action that affect the economy. ${ }^{7}$ Yet such usage is clearly too crude for any rigorous analysis. Even a superficial observation of the differences in the activity of such agencies as the FCC, the ICC, the Federal Reserve Board, the Council of Economic Advisers, and the Justice Department's Antitrust Division reveals that a single term which purports to encompass these agencies' varied activities is useless for purposes of economic analysis.

At the same time we must recognize that law and economics are inextricably related and merely furnish different frameworks of reference for common phenomena. Property, money and credit, contracts, corporations, and other basic elements of the economic order are created and shaped by the legal framework. Correspondingly, many basic concerns of law deal with economic matters. The concept of due process protects property rights; similarly, current legal developments in the areas of equal job opportunities, educational facilities, medicare, consumer protection, 'and control of inflation are directed toward economic goals.

Thus any rational analysis must recognize that law and economics constitute a single system and treat them accordingly. Although the term applied to this system is not of paramount importance, the unitary relationship between law and economics in

5. AT\&T Charges for Services, 2 F.C.C.2d 142, 173 (1965); 2 F.C.C.2d 877 (1966); 4 F.C.C.2d 253 (1966); 5 F.C.C.2d 89 (1966); 9 F.C.C.2d $30 \& 960$ (1967); 11 F.C.C.2d 493 (1968).

6. The parties to the AT\&T rate proceeding before the FCC have nominally reached agreement on the principles to govern the establishment of rates. However, the stipulation is simply a statement of generalities, and the current status of the several proceedings involving $A T \& T$ rates has been described by the most authoritative publication in the field as a "morass." 36 Telecommunications Reports, No. 21, p. 10 (Mar. 23, 1970). Three different proceedings involving AT\& $T$ rates in seven major categories of interstate service are now pending, and the problem of applicable rate-making principles is reappearing as contested issues in all of these proceedings. Id.

7. See, e.g., L. JAFFE, supra note 3, at 4-6. 
modern society should be recognized. The obvious significance and scope of the term "lexonomics" suggest its use for this purpose. The logical implications of the approach which the term implies may be somewhat less obvious and warrant adumbration. ${ }^{8}$

Proceeding upon the assumption that the areas encompassed by the traditional disciplines of law and economics are integrally related, lexonomic analysis seeks to differentiate the various modes of governmental action and to describe the economic effects of such action. If the approach of lexonomic analysis is adopted, several distinct modes of governmental action appear immediately.

First is exhortation, the process of governmental advocacy without coercion. The wage-price guidelines promulgated periodically by the Council of Economic Advisers are a familiar example.

Legislation, the authoritative promulgation of general rulcs enforceable by governmental action, presents the second possiblc mode of lexonomic activity. A prominent example is provided by the antitrust laws.

The third lexonomic mode is government influence on fiscal and monetary policy to provide substantial power over the aggregate economy. By adjusting the balance betwcen governmental expenditures and total receipts, the federal government achieves this control over fiscal or budgetary policy. Similarly, the Federal Reserve Board, an independent body created by congressional legislation, influences the amount of money available - and therefore the flow of the economy-through its monetary and banking policies. The importance of this activity, especially in relation to monetary policy, has recently gained increased recognition.

Fourth is government subsidy which involves payment by the government to either public or private entities on condition that the recipient take specified action. Although subsidization of private enterprise is diminishing, the use of subsidies to secure state cooperation toward desired federal objectives is increasing.

Fifth, the use of both positive and negative tax incentives to accomplish social objectives has also been increasing recently.

A chievement of desired economic effects through use of the government's economic power in the market as a buyer or seller is

8. For a more complete statement of lexonomic concepts and criteria sce Loevinger, Lexonomic A nalysis and Antitrust. 14 ANTITRUST BULl. 313 (1969). 
the sixth mode of action. Examples are government purchasing, imposition of required conditions in contracts between the government and private contractors, and the sale of stockpiled materials to influence price levels.

Seventh is the mode of regulation, the authoritative and coercive action to permit, require, or forbid specified activity. Common examples are the issuance of licenses by such agencies as the ICC and the FCC, the concomitant limitations on the licensees, and the entry of cease and desist orders by those agencies.

Government operation, sometimes called socialization or nationalization, is the eighth mode of action. Governmental control through the ownership of the sole or dominant enterprise in a field or market is generally involved. Familiar examples are government operation of the postal and educational systems.

This particular analysis of modes of lexonomic operation is not necessarily final or definitive, and other theories and terminology might be employed. However, it is important to recognize that government action is not all of a uniform kind and to realize the variety in the potential modes of lexonomic action. As society develops, problems proliferate, and the economic structure becomes more complex, other variant modes of lexonomic action will likely be developed in addition to those currently recognized.

The present law of rate regulation reflects both the complete absence of any theory of regulatory function and the failure to distinguish or consider the numerous possible variants of lexonomic action. For many years the basic law of ratemaking was set forth in Smyth v. Ames, ${ }^{9}$ which held that all calculations concerning the reasonableness of utility rates must be based on the fair value of the property being used for the benefit of the public. The lack of any real agreement on how to determine the fair value of the rate base presented a recurring problem. At various times the courts approved the use of market value, original cost, reproduction cost, and value to a prudent investor. ${ }^{10}$

In 1944 the Hope Gas $^{11}$ case discarded the prescriptions of Smyth $v$. Ames and held that the method by which a regulatory

\section{169 U.S. 466 (1898).}

i0. See generally J. Bonbright, Principles of Public Utiltty Rates 159-71 (1961); Rose, The Hope Case and Public Utility Valuation in the States, 54 Colum. L. Rev. 188 (1954).

11. FPC v. Hope Natural Gas Co., 320 U.S. 591 (1944). 
agency determines what charges are just and reasonable is not important so long as the agency's conclusion is proper. The Supreme Court noted that "[i]t is not [the] theory but the impact of the rate order which counts."12 Without challenging the majority's fundamental approach, three dissenting justices argued that the rates should be fixed to provide more adequate incentives for the efficient production and use of the resource involved. Thus, present law clearly affords a regulatory agency great latitude in its approach to ratemaking. The rates cannot be set so low that the utilities are denied the revenue required for operating expenses and capital costs; neither may the rates be so high that customers of the regulated industry are oppressed by inordinate expense for the services desired. Such indefinite limits invite further exploration.

The typical rate-making case involves the collection of extensive accounting and statistical data as well as volumes of testimony from highly qualified technical experts. These immense records are diligently inspected as if the proper rate will somehow mysteriously emerge in the manner of an ancient hieroglyphic message deciphered by assiduous archeological study. But data do not dictate decisions; even the most thorough scrutiny of the mass of evidence in ratemaking cases never points unequivocally to a particular result. Some animating principle, some theory which postulates the regulatory purpose to be served and constructs a paradigm for achieving that purpose, is needed to direct regulatory action in the light of the paradigm of function and the social purpose sought.

The apparent theory of many commentators and regulators assumes that protection of the public interest compels unyielding opposition to every private interest. While this approach offers both simplicity and emotional appeal by reducing complex technical problems to clear moral issues, it is almost certainly a demagogic fallacy. The public interest is not some great impersonal idol which requires the sacrifice of all private interests. Rather it is an abstraction used to subsume and denominate a judgment representing the greatest good for the greatest number in a particular situation..$^{13}$ A rational approach to the protection of the public interest requires an effort to utilize private interest in motivating actions that will serve the public. The challenge confronting

12. Id. at 602 .

13. See generally SChUbert, The PUblic INTERest' (1960); Loevinger, Regulation and Competition as Aliernatives, 11 ANTitrust Bull. 101, 129-33 (1966). 
regulators is not to frustrate the seli-seeking assertion of private interests but to devise techniques for guiding such poweriul forces toward the achievement of socially desirable goals.

The problem of ratemaking is the establishment of a mode of government supervision, or lexonomic action, which will protect the public against exploitation by a utility operating in a limited entry or monopolistic situation and yet provide incentives for innovation and efficiency by the utility. The most efficient and economical service is not necessarily secured by requiring the use of the cheapest equipment or insisting upon the lowest remuneration to management and investors. Let us take a hypothetical illustration. Suppose a telephone company in need of a large amount of money in order to secure and install costlier and more efficient equipment can attract capital in the money market only by offering a very high rate of return. Permitting the company to secure this money by paying a high rate of return will enable acquisition of the desired equipment, thereby increasing the rate base and profits; but the efficiency of the telephone service will also be increased and may ultimately result in decreased charges to the individual users. In such circumstances the public interest is obviously served by allowing an increased rate base and a higher rate of return. Unfortunately the facts are never so clear as in this hypothetical illustration. Dispute always develops concerning the rate of return required to attract capital and the identification of items to be included in the rate base.

The details of accounting evidence and the testimony of various experts, the traditional bases of ratemaking decisions, fail to reach the fundamental objective of devising an approach that will provide the maximum incentive to the utility to achieve efficient and economical operation. Such operation is not achieved by imposing the strictest or the most detailed regulatory supervision and control. On the contrary, regulated companies, like those in the unregulated segment of the economy, are most likely to strive for improved products and services if given the hope that they may thereby earn the reward of greater profit.

The traditional rate of return approach permits few alternative variations. Under the conventional view, the duty of the regulatory agency is to scrutinize the rate base rigorously to insure that no item is included that can reasonably be excluded and that no amount included is any larger than can be justified by necessity. The rate of return is set at the minimum that will permit capital to be secured 
and that 'will avoid unreasonable or confiscatory use of investors' capital. The rates are then calculated on the basis of these operations.

But this approach furnishes no incentive to improve products or service; on the contrary, the utility's only hope of securing larger profit lies in increasing the rate base. Thus the conventional approach provides a positive incentive to increase the cost of providing service, because the amount allowed as profit is figured as a percentage based on the total capital cost. The more the utility spends for assets comprising the rate base, the greater are total profits. Consequently, the conventional approach establishes an economic incentive for inefficiency. The operation of most regulated utilities in an efficient manner despite the structural disincentives of the regulatory system is a tribute to the inherent integrity of most business executives.

An alternative rate-making approach might be the imposition of a relatively low rate of return without rigorous scrutiny of the rate base or operating costs. This method would provide a temporary incentive to increase profit by reducing operating costs and capital equipment expenditures. However, if the same rate of return were continuously applied to the new reduced rate base, the incentive for operating economy and efficiency would quickly disappear. The utility could advantageously increase its costs and rate base just as under the conventional approach. Thus this approach also provides an incentive to maximize profit by operating inefficiently and increasing costs.

A third alternative contemplates investigation of the rate base and operating costs to insure that only items and amounts actually related to efficient operation are included but permits a wide range of fluctuation in the rate of return. This approach would postulate a reasonable rate of return, and then set rates designed to permit realization of a rate of return equal to or slightly greater than that required minimum. The rate of return could then increase within a relatively wide range so long as the actual rates charged users did not increase and the service continued to improve. The approach offers some economic incentive for improving service and increasing efficiency and economy in operation, since both the public and the company share the resulting rewards. However, when the company reached the upper limit of its permissible rate of return, the rates would again be reduced. 
Other considerations also support the range of permissible return approach. First, no regulatory agency can foresee the future with clarity and confidence. When a regulatory agency relies upon strict supervision of rate base, rate of return, and service charges, it incurs the burden of constant oversight and continuous consideration of changing economic circumstances. Allowing fluctuation of the rate of return within a wide range relieves the agency of the necessity of reexamining the rate structure with every change of economic circumstance and compels reconsideration only at much longer intervals. Second, the agency possesses neither the data nor the techniques for arriving at a proper specific rate of return. An elementary principle in science and statistics states that the results of a mathematical operation can be stated with no greater precision than that of the least precise factor or number used in the operation. ${ }^{14}$ Testimony concerning the rate of return represents estimates of businessmen, economists, and statisticians. Such estimates are based on masses of data and, in some cases, on prodigies of mathematical ingenuity in devising formulas. However, the data are usually derived from businesses only remotely comparable or roughly analogous to the utility, and the formulas used contain variables that depend upon the transformation of subjective judgments into quantitative terms. Evidence of this kind does not logically support a determination stated in very precise numerical terms, but only a broad and imprecise judgment.

Thus the public purposes of regulation, current economic theory, and the logical limitations of inference combine to require that a rate of return be established only within a relatively wide range of permissible variation. Furthermore, establishing a range of reasonableness for a rate of return clearly does not imply that any rate beyond that range is ipso facto unreasonable. There may be inadequate evidence or an unwillingness to decide that particular rates are reasonable and also no proof to determine that they are unreasonable. In most cases the evidence will show that a fairly wide

14. For example, an observer might stand on a street corner and estimate the weight of each person who passed by. If all estimates were recorded, they could be added and averaged and the result could be stated mathematically to three, four, or more decimal places. However, it would be misleading and quite unscientific and illogical to state the results in such a fashion. At best, the results of such a process could not properly be stated any more closely than in pounds, not in ounces or fractions of a pound. The evidence in rate cases in many respects resembles the kind of data that might be gathered by an eye witness estimate of the weight of passersby on a strcet corner. 
range of rates is reasonable under the conventional view; that on each side of this range exists another range that is not clearly reasonable or unreasonable; and that only rates considerably beyond the range are clearly unreasonable. Although this conclusion seems compelled by experience with actual rate cases, by the limitations of statistical inference, and by the desirability of establishing incentives to efficiency, it goes considerably beyond the position that the regulatory authorities have been willing to take thus far.

Even this modified version of rate of return ratemaking does not provide a wholly satisfactory solution or promise to satisfy all the criteria of lexonomic action. No matter how applied, the rate of return approach to ratemaking involves a tunnel-vision analysis which distracts the ratemaking process to such esoteric issues as whether the cost of services should be based on fully distributed or incremental costs and whether investment credit and accelerated depreciation used for tax purposes should "flow through" to current customers or be "normalized" by accounting procedures. The answers to these issues are truly arcane and without rational principle for sensible determination. Conflicting views represent no more than the particular prejudices and interests of the parties; the inordinately complex and voluminous arguments are simply verbal facades to mask the arbitrary nature of the choice.

Fresh thinking by the most creative minds in the field of lexonomics should seek to develop a new functional paradigm which will offer a choice of alternatives to the traditional scholastic dispute concerning the amount of profit that can be balanced on the pinhead of conventional rate-making dogma. While the precise approach that may prove most useful cannot be stated, some of the characteristics of any useful approach can be described and some possibilities for further discussion and exploration may be suggested. This need not be as difficult as it seems. A great deal can be learned by using the scientists' method of hypothesizing and engaging in conceptual experiments. To take a very simple, extreme, and impractical example, suppose that dividends on the stocks of all regulated utilities were exempted from, or given special tavorable treatment in, the federal income taxation statutes. What would be the result? Obviously such stocks would become much more desirable and increase in price with no change in service or rate of return. Without any action by a regulatory agency, the rate-making process and the positions of both stockholders and customers would change drastically. 
For another result, postulate action by the Securities and Exchange Commission requiring that all expenditures for capital equipment be charged to expenses in the year incurred. This would be accelerated depreciation with a vengeance. Without a change in rates, profits would plummet and stock prices would surely follow. While neither of these hypothetical possibilities is either practical or wise, this highly abbreviated analysis suggests the insight that may be gained by the conceptual technique.

One alternative to rate of return ratemaking is limitation of the profit margin. Rate of return ratemaking is based on a regulatory obsession with the investor. The theory considers it wicked, or at least unfair, if the investor makes too much money on his investment. While some regulators are also concerned that the investor should not receive too little, rates are generally set less to protect the consumer than to frustrate the investor. As previously noted, this results in establishing incentives for high cost operation and inefficiency. No regulatory method effectively guards against this or seriously attempts to prevent it. Under present theory, the ends of regulatory action are satisfied so long as the investor does not receive excessive profits, regardless of the degree and cost of service to the customer.

But rate regulation exists because the utility has a monopoly position and is not subject to the check of competitive market forces. Theoretically the regulatory agency is using its legal power to provide some of the same effects achieved by economic forces in a competitive market. However, while the competitive model focuses on prices, the regulatory process suffers inherent weaknesses through its concentration on gross profits or rates of return in attempting to regulate prices.

A regulatory agency could limit the utility's profit margin by an order that no charge to the public for any commodity or service ${ }^{15}$ could include more than a specified maximum percentage or amount of profit to the utility by any acceptable method of accounting: Superficially this may sound like rate of return ratemaking, but it is actually quite different. To begin with, profit margin limitation does not involve the regulatory agency in the impossible task of

\footnotetext{
15. "Commodity" and "service" are probably tautological terms since, in economic theory, commodity includes service. However, the terms are frequently used in legal discussion as complementary and no significance is to be attached to their use either together or singly in this discussion.
} 
attempting to analyze and validate the rate structure. Profit margin limitation would not impose the rigidity on rates characteristic of conventional regulation. While this approach requires no particular method of accounting, it probably would encourage the use of fully distributed costs in order to minimize the profit margin. Most important, however, profit margin limitation provides incentives for innovation, efficiency, and rate reduction.

Under conventional rate-making principlcs, any reduction in expenditures for capital equipment reduces both the rate base and the resulting profit the utility is permitted to make. A new invention providing better service for a fraction of the utility's historical cost is catastrophic to the utility under this system. The satellite communications industry offers a practical example. Satellites promise to provide future transoceanic circuits much more cheaply than older cable circuits. The satellite communications companies will be permitted to charge rates and make a profit only on the basis of thcir investments. Consequently, Comsat and the established communications carriers are engaged in a bitter struggle for the right to invest in the ground stations, the most expensive part of the satellite system. The greatest single problem confronting Comsat, as a regulated utility, is not the development of new technology but the problem of investing enough capital to establish an adequate rate base.

Under profit margin limitation the incentives would be reversed. Certainly initial determination of the reasonable profit margin will involve great disagreement and possibly bitter dispute. But once the profit margin has been set by legal action, the utility could maximize its gross profit by attaining the greatest efficiency and economy, cstablishing the lowest prices or rates, and securing the greatest volume of business. Under this rate-making theory, an invention providing better service at lower capital cost permits a rate reduction without a significant decrease in return to the utility and encourages an increase in overall business limited only by the elasticity of demand. The aggregate profit to the utility increases as does the rate of return based on the decreased capital cost. Moreover, while the efficiency of the utility's service increases and both the utility and its stockholders concomitantly earn a greater profit, the cost to the customers will decrease. Thus technological improvements confer a financial benefit on not only the customers but also the utility and its stockholders. This approach to ratemaking could probably 
minimize, if not eliminate, the present conflict between the communications carriers and Comsat.

Another alternative approach to ratemaking might be to control or limit the rate level by maintaining rates at a constant ratio to the general price level. Rate reductions would naturally be permitted and might even be encouraged by some device such as relieving the utility from imposition of an excess profits surtax on increases in overall profits during any year in which the rate level declined relative to the general price level. This approach would probably involve greater rigidity in the rate structure than profit margin limitation, but it provides greater incentive to efficiency and economical service than the present conventional approach. Described most simply, rate level limitation permits the utility to earn overall profit without limitation so long as constant dollar rates to the consumer remain steady or decrease and service is maintained. This reverses the present approach and directs regulatory action to securing satisfactory and economical service to the public rather than merely preventing the stockholders from receiving too much.

Ultimately, however, any theory is probably insufficient to enable a government bureaucracy to supervise a pricing decision with the wisdom rate regulation requires. Other lexonomic modes or devices are much more likely to provide the means for controlling prices in monopoly situations. One such possibility is a legal requirement for competitive procurement of equipment and supplies. Such a requirement has been imposed by statute on Comsat and seems to be fairly effective. Of course, competitive procurement introduces market forces into only one aspect of monopolistic situations. However, the stringency and scope of regulation are correlative to the strength and extent of the utility's monopolistic power. Competitive procurement and stringency and scope of regulation thus are trade-offs with greater competition-in procurement diminishing the need for extensive regulation.

Beyond this, lexonomic analysis may suggest a way to approach elimination of the need for utility rate regulation altogether. Because physical or economic factors limit the market to a single telephone, telegraph, electric power, gas, or other utility service, the utility is the only source of a needed commodity or service and competition is impossible or impractical. The customer, having no alternative, must buy from the utility at any price set and has no economic power to influence that price. Thus the customer turns to the 
government for legal power to influence the price. The regulatory agency is a remote, ambivalent, unrepresentative, and ineffective surrogate for the customer. If a means could be devised to give the customer direct representation and effective power to influence prices and service, rate regulation would be undesirable and unnecessary.

Such customer power can be established by a fairly simple means. If the customers of a utility were allowed to elect representatives to the corporate board of directors, they would probably be better informed and more influential over prices and service than any government regulatory agency. An experimental approach to this device might be implemented by a statutory provision allowing a utility providing for customer elected directors in its corporate structure to be exempt from regulatory rate control. ${ }^{16}$

The idea of "outside" or "public" directors is, of course, rather common. The Communications Satellite Act of $1962^{17}$ provides that Comsat shall have three directors appointed by the President of the United States,$^{18}$ although whether these directors represent the government or the public is unclear. In any event, the idea of corporate outsiders sitting on a board of directors is neither unprecedented nor impractical.

While the situation may have been different in an earlier era, the utility's customers appear to have as great a financial stake in the utility as its stockholders and to be entitled to some voice in its operation as a matter of equity. Indeed, this theory is the conventional justification for rate regulation by the government. If the stockholders and the customers each elect an equal number of directors, the customers will possess power over rates and prices at

16. It should be noted that this suggestion of customer elected directors was made when this paper was first presented at the Iowa State University Conference on Public Utility Valuation and Rate Making, on April 24, 1969, which was prior to the recent effort to elect "consumer" directors to the General Motors board to represent consumer interests and other objectives considered socially desirable. There is a significant difference between the proposal to put directors on the board of an unregulated business corporation to pursue vaguely defined social objectives and the proposal suggested here to substitute customer elected representation for bureaucratic regulation with respect to rates and services of regulated public utilities. However, the interest aroused by the campaign to put "consumer" directors on the boards of business corporations indicates at least the probability that there will be sufficient customer interest in the election of directors to utility boards to provide the possibility of successful operation of such a plan.

17. 47 U.S.C. $\S \S 701-44$ (1964).

18. Id. § 733(a). 
least equal to their power in a competitive market. In all probability, the customer representatives' interest will concentrate on quality and efficiency of service as much as lower rates. In any event, representatives would have access to all relevant data and share in ultimate control of operating and pricing policy. Furthermore, the single purpose and private status of customer elected directors frees them from the political pressures and ambitions that intrusively motivate some regulators. Thus the need for government regulation of rates would disappear.

The device of customer elected directors on utility corporate boards obviously is most easily adopted by telephone, electric power, and other utilities with a readily identifiable and stable group of customers. Customer elected directors would be more difficult to provide for air lines, railroads, and similar enterprises with temporary and transient customers. However, if the concept should prove practical, ingenuity could adapt it to the varying situations of different utilities. Compared to the present system of rate regulation, customer election of utility directors promises to be simple, nonpolitical, non-bureaucratic, and effective. Further consideration is certainly merited.

Analysis should not ignore the ancient principle that no government agency is ever wholly abolished or deprived of all functions. Undoubtedly attendant difficulties and problems will arise in establishing a system of customer elected directors and in conducting elections among utility customers. The regulatory, agencies might conveniently and appropriately supervise the establishment of the system and oversee the vote, somewhat as the National Labor Relations Board now supervises voting in the election of labor union representatives. Perhaps the most effective action a government agency can take to regulate utility rates is to supervise the election of customer elected members of the utility's board of directors and thereafter engage in the collection and publication of statistics about utility rates. 
